Ricardo Donoso

\title{
Barros Arana y sus detractores
}

OCOS escritores americanos tienen una vida más noble y elevada, consagrada toda ella al cultivo de las letras. del espíritu, a la enseñanza y al servicio de su patria. que don Diego Barros Arana. Periodista en sus mocedades, cuando el reaccionario gobierno de Montt pesaba como una losa sobre el país, educador, hombre de pluma, diplomático. no hubo esfera de la actividad cultural en la cual no dejara una huella imborrable y profunda.

Tuvo Barros Arana la fortuna de contar con un padre que no pretendió torcer la orientación de su vocación literaria, y que. por el contrario. la facilitó en cuanto estuvo de su parte. No era el de Chile. en los días de la. Tormación intelectual de su futuro historiador, el ambiente más propicio para dofar de una sólida cultura literaria y cientifica a quien la hubiera menester. Es cierto que el doclo Bẹllo ejercia su influencia bienhechora y que el inquieto Sarmiento habia revelado ya a la juventud literaria las promesas que encerraba la literatura europea de esos dias; pero la enseñanza en el Instituto Nacional adolecia aún de todos los resabios de las disciplinas coloniales, con su indigesto latín y los horrores del sistema laucasteriano. Para la formación de su personalidad intelectual no contó, pues. Barros Arana, más que con su decidida vocación literaria y su voluntad de hierro, que hicieron de él el más perfecto aulodidacta.

Ya en los años de su recloría del Instituto Nacional, bajo 
la administración de don Joaquín Pérez. fuvo Barros Arana ocasión de reñir porfiadas jornadas para sostener las reformas que habia encarado en la enseñanza, pero el partido clerical consideró que su presencia al frente del primer eslablecimiento de segunda enseñanza del pais importaba una amenaza para la conservación de la fe de la juventúd que acudia a sus aulas y para el mantenimiento de las venerandas tradiciones coloniales. No bien llegó al poder uno de sus miembros, se inventó cualquier prelexto para hacer imposible la permanencia del eminente educador en aquel puesto.

La hostilidad de los clericales contra Barros Arana no es. pues, cosa de hoy. sino muy antigua: lo combatieron, con buenas y malas armas, durante la Administración Montt: lo caracterizaron como un elemenlo desquiciador durante los dias de su rectoría del Institulo Nacional; combatieron sus reformas en la enseñanza pública: criticaron sus obras, negándoles todo valor posilivo, y hoy. transcurridos casi cualro lustros de su muerte. se pretende repudiar su vasta, enorme y trascendental labor literaria. y colocar su nombre a la altura del de cualquier coleccionista de papeles viejos de tres al cuarto.

Muchos han sido los detractores que ha tenido el prolijo historiador de Chile, pero ninguno de ellos más obstinado y tenaz que el autor de los Estudios sobre la literatura chilenas. A lo largo de las páginas de su reciente volumen, en cada ocasión que se presenta, aunque sea traida por los cabellos, las emprende rudamente contra Barros Arana, contra su concepto de la historia, su método de composición, su labor docente y su estilo. Antes de analizar los reparos quedon Pedro Cruz formula contra Barros, recojamos algunas de sus observaciones, que corren desperdigadas en el mismo volumen, y que no andan muy lejos de hacerse fuego unas a otras.

En su esludio sobre don Miguel Luis Amunálegui nos dice Cruz que sin estar bien esclarecidos los hechos de la historia 
nacional, como no lo estaban entonces. en la época en que el autor de La reconquista española, escribía, los argumenlos de Lastarria parecian asentados en el aire. El rector de la recién fundada Universidad, sigue diciendo. trafaba por su parte de dirigir los estudios históricos por el buen camino: se empeñaba en que comenzaran por donde debian comenzar, esto es. por el esclarecimiento cabal y exacto de los sucesos. por la investigación desapasionada y la simple narración. Lo demás vendria más tarde; por lo pronto era preciso atender al acopio de materiales y a echar los cimientos». Precisamente ésta fué la labor que se impuso Barros Arana y que realizó con amplio éxito, pero lo que para Lastarria es un reparo. para el aulor de la .Hisloria general de Chiles, no será un elogio. En la labor de Lastarria no hay hechos que sostengan las ideas; en Barros Arana, al revés, los hechos oscurecen las ideas fundamentales: Barros Arana es incapaz de elevarse a las grandes sintesis: Barros Arana carece de espiritu filosófico: Barros Arana se confunde en los detalles. Su presunción y la facilidad para asimilarse doctrinas que otros idearon después de largos esludios y hondas meditaciones, dice el critico hablando del aufor de los -Recuerdos literarios.. lo llevaron a descuidar la investigación prolija, los estudios fundamentates. la labor comparativa, el mélodo, y en fin. todo aquel trabajo preparatorio del hombre verdaderamente cientificos. Aqui tenemos, pues, apuntados a la cuenta de Lastarria, como altísimos defectos. las cualidades sobresalientes que caracterizan al espiritu y la lendencia investigadora de don Diego. Es fácil constatar cómo las opiniones del crifico se hacen fucgo en estos estudios de ambos escritores: es que no es que un principio de sana y alta crítica lo guia. sino el propósito de acumular reparos y objeciones, apostillas y glosas, movido siempre por el ardiente celo de su fin religioso.

Apuntemos antes de seguir adelante que el largo articulo que el critico consagra a nuestro hisloriador se refiere sólo a los once primeros volúmenes de la .Historia general de Chile, que han servido para saciar su âvida curiosidad. Tales volúmenes 
constituyen sólo una tercera parte de la vasta labor literaria del eminente escritor y hombre público, y cualquiera que sea la opinión que merezcan ellos al critico. mal podría tomarse como un juicio definitivo sobre su obra literaria.

Tarea fastidiosa es la de seguir al crítico a lo largo de sus argumentaciones, cuyo propósito fundamental es el de acumular reparos, sin más fundamento que la ojeriza profunda que siente hacia el autor estudiado.

La historia general de un pais, aun cuando éste no tenga más que unos cuantos siglos de existencia, no es labor para un hombre solo: por eso. en las naciones de mayor cullura, se han encargado de ella corporaciones sabias. cuerpos doctos. academias o grupos de individuos animados de aficiones similares. En los paises de habla hispana esta labor se halla sólo iniciada y apenas si dos o tres cuentan con una historia general como la de que se enorgullece, con tan justos titulos, la nación chilena. Dor la preparación y laboriosidad que requiere, por la enorme faena de investigación y búsqueda que ha menester. la composición de una relación del desenvolvimiento hislórico de una nacionalidad, es una tarea que basta para llenar una vida entera. Tal fué el caso de Barros Arana: despućs de estudiar los archivos nacionales y extranjeros, de reunir una valiosa colección de libros americanos, de adquirir una cultura sólida en casi todos los ramos del saber humano, inició su labor, que fué digno remate de su vida de escritor. Su . Historia general de Chile, fué el fruto de treinta años de investigación, de labor preparatoria, y de cuatro lustros de paciente realización.

El crítico no nos dice cuál es para él el historiador ideal, ni se detiene mayormente a apuntar su concepto fundamental de la historia. ¿Es ésta un género literario, o es una labor cientifica? ¿Macaulay. Buckle. Taine. Boisier, Renan son historiadores de su devoción? Interesante sería saberlo. pues ya que nuestros historiadores le resultan tan delestables, bueno seria que quedáramos enterados de quiénes son para él los maestros del género. Dice Cruz que la historia que se limita a investigar los sucesos y a exponerlos en orden cronológico. 
no requiere inspiración, ni miras superiores, sino paciencia. constancia, orden, método y cierta sagacidad para seguir la pista a un hecho a través de los documentos. Es verdad que se requieren todas las condiciones apuntadas: pero agreguemos también que para merecer el calificativo de historiador. se necesitan además otras condiciones, muy dificiles de hallar. y que Barros Arana reunió en grado eminente: elevación de ideas. tolerancia, comprensión, probidad moral, y. por encima de lodas. amor a la verdad y exclusivamente a la verdad.

Después de discurrir buen número de páginas. Cruz las emprende contra nuestro hisloriador por su pretendido espíritu antireligioso. Vemos ya claramente los molivos que mueven la pluma del descontentadizo crítico: su credo religioso no le permile aceptar las conclusiones a que llega el escritor. Sin embargo. dice. su propósito de limitarse rigurosamente a la aclaración de los hechos, no ha sido tan firme que resistiese a un espiritu de propaganda excéptica y antireligiosa. que. aun cuando no penetra la obra, aparece en ella de trecho en trecho como desagradables excrecenciass. Desagrada profundamente al surcidor de reparos el hecho de que Barros Arana inicic su historia general de Chile con el origen del hombre americano y los aborigenes de Chile: esto no está de acuerdo con lo que enseña la Biblia y acepta la Iglesia Calólica. Conclusión: Barros Arana es un espíritu descreido y tendencioso, que no ha pretendido más que lastimar a una religión que es stan antigua como el mundo, y a los millones de seres que creen en sus dogmas.

El que Barros Arana no crea en los milagros y el hecho de que afirme que la fe ciega que se tenía en ellos durante la conquista y la colonia, sea algo caracteristico de las creencias religiosas de una época, saca de quicio al señor Cruz. . Comprobada plenamente. como lo está, dice. la inspiración divina de los libros santos, queda comprobada por el mismo hecho la verdad de estos prodigios.. ¿Estamos leyendo alguna cróca milagrosa de la Edad Media. o un indigesto engendro de algún fraile pendolista? 
No. señor, esto lo consigna un ciudadano en letras de moldè en pleno siglo XX.

Es también harto molesta para el crítico la circunstancia de que Barros Arana refiera con más o menos minuciosidad las prácticas religiosas de la colonia e infiera de ellas algunas conclusiones sobre las costumbres de la época. Reconoce que cuando ́́rata de asuntos políticos es bastante discreto, pero que pierde su imparcialidad cuando se ocupa de cuestiones sociales a religiosas. Para un católico tan ferviente como el señor Cruz. para un espiritu tan intransigente y tan ajeno de tolerancia, la probidad moral. la sinceridad y el amor a la verdad demostrados por Barros Arana, son punto menos que inaceptables. Juzga Cruz la labor literaria del historiador de Chile con un criterio tan estrecho. desde su punto de vista de obediente calólico, para quien antes que nada están los dogmas proclamados por la Iglesia, que es imposible exigir de él elevación de ideas, amplitud de miras y espiritu de comprensión. Pero es tan imponente la erudición del historiador de Chile, tan grande la autoridad de su palabra, tan enorme su caudal cullural, que el crítico no puede menos. eso sí que a regañadientes, que reconocerlo. Aludiendo al volumen en que el eminente educador se ocupa de las correrias de los filibusteros en las costas de Chile, escribe: Tiene una erudición asombrosa, abrumadora. No hay ninguna de estas naves extranjeras cuya historia no conozca hasta en sus más infimos pormenores. No podria dar razón más cabal y completa de esas expediciones, aun cuando hubiese tomado parte en cada una de ellas. Las relaciones escritas por los navegantes. las obras publicadas acerca de ellos, los mapas, derroferos, libros náuticos, todo ha sido examinado por Barros Aranas.

Más adelante Cruz dedica un párrafo a la expulsión de los jesuitas: no objeta la relación de Barros Arana. limitándose a calificar aquella medida de injusla: pero como no debe haber estado muy bien enterado del asunto. a pesar del piadoso interés que le merece la orden, escribe: LLas causas de esta injusta expulsión corresponden a la historia europea.. A la historia europea y americana, agregaremos nosotros, y en atención 
a esta consideración Barros Arana las apunta minuciosamente: pero el escritor católico no se atrevió a desmenuzarlas. Más adelante veremos cómo esfe mismo asunfo de la expulsión de los jesuitas dará a otro de los detractores de nuestro gran historiador, tema suficiente para formular extensas consideraciones.

Pedro Cruz en su largo articulo, no sólo se reduce a estudiar la labor histórica de Barros Arana en sus once primeros volúmenes de la sHistoria General de Chiles. sino que entra a dilucidar tópicos de alta y permanente significación. tales como el relativo al régimen colonial de España en América y a la vida colonial. Ya en un articulo anterior hemos allegado algunas citas peregrinas, que demuestran que para Cruz el régimen colonial fué poco menos que ideal. pues èl nos dejó un legado magnifico: la religión católica. El atraso en que vivieron las colonias hispano-americanas se debió. según él. a muchas causas, sajenas todas ellas al absolutismo y lirania. No hubo en la colonia movimientos de rebelión, ni espiritus altivos que abominaran de ese régimen; el trastorno que intentaron realizar en Chile los franceses Berney y Gramusset, no pasó de una burda y descabellada aventura. Los propósilos de esos-soñadores. iqué mordaz sonrisa y qué sangrienta piedad merecen al critico católico! Escritores mal intencionados, escribe, han sacado ven. taja de esto. no tanto por animadversión a España. como por odio al legado más precioso que ella nos dejó. y onte el cual todo lo demás es nada: la religión católica. Quieren hacernos creer que la sociedad, colonial, esencialmente católica, era profundamente desgraciada. Le dan un tinte sombrio como si hubiese estado sometida a constante opresión y espionaje; la presentan como rebaño de hombres serviles, santurrones, ignorantes y supersticiososs. Es sensible que del esludio de las costumbres de la época colonial se desprenda un cuadro tan poco del agrado del critico, que parece ver en ellas un soñado paraiso, con muchas procesiones, novenas, rogativas, rosarios. golpes de pecho $y$ olor a incienso.

El hecho de que Barros Arana reconozca y proclame la in- 
fluencia de los filósofos del siglo XVIII en el movimiento que dió origen a la independencia de Chile, merece a Cruz una amarga sonrisa escéplica. ¿De varias partes de la .Historia General, he podido colegir que nuestro autor reverencia muchísimo a los filósofos del siglo XVIII. escribe. Es natural que trate de hacernos creer que a ellos debemos en gran parte la revolución de la independencia. Ahora bien, no hay hechos que lo compruebens. ¿Y acaso la independencia misma no es un hecho, el más notable y magnifico de todos ellos? ¿Queda evidente, escribe un poco más adelante, que la revolución de la independencia tuvo muy poco que ver con las doctrinas filosóficas del siglo pasado, ni con los principios proclamados en la revolución francesa del 89. Esto lo escribia el critico en 1895 : es probable que entonces esluviera un poco olvidado de sus lecturas históricas. Hoy resulta aquella una afirmación lemeraria imposible de sostener. En las páginas siguientes continúa Cruz cavando en el mismo tema y pretendiendo. probar la revolución de la independencia de una manera original y personalisima. muy de acuerdo con sus preocupaciones y arraigados prejuicios. Mientras tanto, apenas si es necesario recordar la obra de los primeros periodistas de la Patria Vieja, Camilo Henriquez e Irisarri, en cuya labor literaria se advierte en forma tan decisiva la influencia de las ideas de los filósofos del siglo XVIII. Además, es un hecho probado que los hombres más cultos de aquella época, y que desempeñaron papeles destacados en la independencia, estaban familiarizados con los escritos de los enciclopedistas y demás lamosos filósolos de aquel siglo. Don José Antonio de Rojas, don Manuel de Salas, don Juan y don Mariano Egaña. Camilo Henriquez. Irisarri, don José Miguel Infante, don Juan Martinez de Rozas, y-loh imperdonable herejia para don Pedro Cruzl-el mismisimo padre Francisco Javier Guzmán. leyeron y saborearon las páginas de Diderot y D'Alembert, del barón de Holbach y Rousseau, de Helvecio y Montesquieu. Muy interesantes y reveladoras son en este sentido las cartas que publicó en un estudio reciente, intitulado -Génesis de la independencia de Chiles, don Domingo Amuná- 
tegui. y cuya lectura no puedo menos de aconsejar encarecidamente al descontentadizo critico.

Remata Cruz su estudio sobre Barros Arana con estas palabras: .Con esto termina el volumen undécimo de la Historia General de Chile, obra de labor inmensa y de gran sagacidad en la investigación; pero sin vida. Le falta el corazón y el pensamiento,. No era Barros Arana hombre de sensibilidad arlistica, ni pretendió hacer de su obra capilal una labor de alto mérito literario, por lo que mal pueden buscarse en ella una esmerada factura, ni un estilo trabajado. Lo que preocupó fundamentalmente a nuestro historiador fué la investigación de la verdad, empresa en la que obluvo singular y duradero éxito. No tuvo tampoco don Diego el propósito de componer una obra filosófica ni sacar conclusiones de indole sociológica. Determinar los hechos, señalar sus causas y consecuencias, ajustándose a una tendencia puramente cientifica, tales fueron sus propósitos.

Otro de los detractores de Barros Arana es don Carlos Silva Cotapos, alto dignatario de la Iglesia, quien exhibió hace años. en 1913. en un menudo folleto. sus opiniones sobre nuestro eminente historiador. Historiador también, a su manera. el señor Silva Cotapos rechaza en el autor de la .Historia General, su tendencia antireligiosa, tachando su obra de tendenciosa y animada por un espiritu de sectarismo, lo que no es un obstáculo para que sus páginas estén redactadas con una violencia de lenguaje muy poco de acuerdo con los propósilos evangélicos de un Ministro de la Iglesia.

Reconoce el señor Silva Cotapos que Barros Arana tiene un estilo claro y exhibe con orden los hechos; elogia su labor de investigación. pero critica, injustamente. su afición a transcribir documentos. Este último reparo es sobradamente injustificado: de todos nuestros historiadores. Barros Arana es el menos aficionado a copiar documentos, tendencia muy explicable por la 
ley del menor esfuerzo. pero que no reza con nuestro escritor. Cada vez que Barros Arana acude a los documentos los resume, los extracla, los reduce a unas cuantas lineas, y sólo los transcribe en su integridad cuando su importancia aconseja no mutilarlos, ni citarlos truncos. Vicuña Mackenna y Amunátegui, particularmente este último, si que han sido amigos de copiar y acumular documentos, para abultar sus obras con un pesado aparato de material erudito. Pero la tacha fundamental que el obispo de Talca formula a Barros Arana es su espíritu antirreligioso: dice no sólo es un racionalista y un hombre sin fe, sino un enemigo del cristianismo. Este mal espíritu. escribe, esle perverso genio que inspira al señor Barros. le olusca a pesar de sus esfuerzos por no apartarse de la verdad. y le hace incurrir en gravisimos defectos. El, que es guía casi siempre seguro cuando escribe la historia civil, apenas pone el pie en la historia ećlesiástica o aparece alguna sotana. ve desvanecerse su imparcialidad y ya no gasta ese meticuloso esmero por informarse de la verdad y expresarla con exactitud. Así. en historia eclesiástica, su testimonio es sospechoso por parcial y a veces por mal informados. Planteada la cuestión en esle terreno es difícil conciliar las opiniones: el señor Silva Cotapos. siluado en su estrecho punto de vista de ferviente católico. ve heridas y lastimadas sus creencias con las simples apreciaciones del historiador, mientras que éste, guiado sólo por su propósito de descubrir la verdad y exhibirla, no vacila en manifestarla. Para probarnos el espiritu antirreligioso del autor del .Proceso de Pedro de Valdivia.. el autor allega tres citas, de los tomos I y II de la .Historia General de Chiles. IFlaca y précaria prueba en una labor tan extensa como la de nuestro escritor. que ocupa treinta y dos grandes volúmenes!

Dice el señor Silva Cotapos que la expulsión de los jesuítas de los dominios del rey de España es otro de los temas en que Barros Arana shace prodigios para atenuar la gravedad del atentado y escamotear la verdad al lector desprevenidos. A este asunto consagró el historiador de Chile el capitulo XI del tomo sexto de su magna obra, y quienquiera que lo lea con ánimo 
desapasionado y frío, no podrá menos de admirar en él la enorme labor de investigación que importa, la claridad de la exposición y la duradera luz de eterna verdad que despide. Barros Arana no atribuye aquella trascendental medida a la obra de los filósofos innovadores del siglo XVIII, sino a la influencia de los principios regalistas que dominaban en el Gobierno peninsular. Silva Colapos, por su parte, dice que la expulsión de la Compañía de Jesús se debió a la mentecatez de los Borbones y a $l_{a}$ malicia de sus ministros, fieles discipulos de Voltaire, el más pérfido y más embustero de los franceses. Barros Arana investiga pacientemente, apunta las causas aparentes y reales, señala los motivos, y llega a la conclusión de que aquella medida se explica por la influencia de las ideas dominantes en la corte española, y por la suma enorme de poder que los jesuítas habian llegado a tener en sus manos por la acumulación de cuantiosos bienes; mientras que su critico sólo atina a vituperar violentamente a los autores citados por el historiador, sin aportar ninguna consideración valedera. El verdadero móvil de sus acciones, escribe refiriéndose a los ministros españoles de Carlos III. Tué la impiedad, el odio al cristianismo y la ridícula vanidad de merecer los elogios de Voltaires. Y en prueba de ello. cila. ¿a quién creerá el lector? Nada menos que al mismisimo don Marcelino Menéndez y Pelayo. paradigna de escritores vehementes y apasionados, cuya intransigencia de espíritu y fanatismo religioso fueron las cualidades caracteristicas de su admirable pluma. Un escritor desapasionado, guiado sólo por el afán de hallar la verdad, busca ésta en otra parte y no se limita a estampar declaraciones huecas de sentido y hueras de significación. Tales escritores existen y en prueba de ello permitasenos citar las palabras que don Valentin Urtasun, historiador peninsular. consagra al conde de Floridablanca y que bien pueden aplicarse a don Pedro Pablo Abarca de Bolea, conde de Aranda, cuya acción política arranca tan agresivas palabras al escritor eclesiástico. Floridablanca. escribe el escritor peninsular nombrado, absolutista convencido. no admitia que el poder real sufriera en su ejercicio augusto influencias que vinieran a 
mermarle o desnaturalizarle; entendia que en lo temporal era imposible tropezarse con oposiciones, y a idea tan clara y arraigada respondieron sus convicciones regalislas y su empeño en manlener en la organización del Estado una superioridad eminente de la polestad del monarca, con prohibición de que fuera atacado ni discutido por ninguno de los funcionarios y corporaciones, que le debian no más que acalamiento y obediencias.

Las demás objeciones que el señor Silva Cotapos hace al historiador de Chile se refieren a asuntos bien insignificantes. y están destinadas a probar que éra lego en derecho canónico. El biógrafo de don Manuel de Alday no opone reparos a los hechos referidos por el historiador. sino que se detiene a desmenuzar las apreciaciones que aquellos merecen a Barros Arana. Creo que no restarán autoridad ni gloria al erudito autor de la ..Historia General, los pocos puntos que calza, a juicio de su critico, en materia de derecho canónico. En la enorme labor literaria de Barros Arana el señor Silva Cotapos apenas si ha logrado zurcir este o aquel reparo, siempre en cuestiones de mera apreciación. En los 16 volúmenes de la .Historia General, sólo encuentra esta o aquella menudencia: el material para sus demás observaciones se lo proporcionan las páginas de eUn decenio de la historia de Chile,. y de la biografia de don Rodulfo Armando Philippi. ¿A qué conclusión arriba el escritor eclesiástico? Comulga el señor Silva Cotapos plenamente con la opinión de su predecesor en la misma labor. don Pedro N. Cruz, en el sentido de asignar a la .Historia General de Chile, el calificativo de excelente en su especie, la del género narrativo. qque ocupa un grado inferior en el género histórica,, agregando por su cuenta que la pasión antirreligiosa lo hizo incurrir en errores y falsas apreciaciones que deslustran su mérito y obligan al lector a mirar con desconfianza sus asertos. cuando trata de asuntos religiosos o siquiera remotamente relacionados con la religión. 
Don Pedro Cruz, con la autoridad de su palabra, asienta que el género narrativo ocupa un grado inferior en el género histórico. ¿Qué sistema o qué género ocupa los rangos superiores? El crítico no lo dice, como tampoco nos revela cuál es su ideal en la materia. El hecho es que no hay tal género narrativo y que los conceptos sobre la manera de escribir la historia han cambiado en las distintas épocas. Primeramente la historia fué concebida como la narración de los hechos memorables, destinada a conservar el recuerdo de una colección de precedentes. cuyo conocimiento serviria de preparación práctica para la vida. El historiador se proponía agradar o instruir, o ambas cosas a la vez, y no daba gran importancia a las pruebas. Tal fué el concepto que tuvieron Plutarco y Tilo Livio. Durante el Renacimiento los historiadores no hicieron más que imitar a los antiguos, y siguieron considerando la historia como un mero arte literario, sde tendencias apologélicas o de prelensiones didácticas». Es necesario llegar al siglo XVIII para advertir una ampliación del concepto de lo que debe ser el contenido histórico. Los escritores y filósofos de esa centuria consideraron el pasado. no sólo como el estudio de los sucesos en sí, sino de los hábilos de los hombres: Montesquiẹu y Voltaire son los más destacados representantes de esta tendencia. En el mismo siglo XVIII aparece ya por primera vez la expresión de shistoria de la civilizacións. La influencia del romanticismo alcanzó también, en las primeras decadas del siglo pasado, a los historiadores, y entonces acudieron a medios de exposición más vivos, destinados a impresionar y conmover a los lectores, procurando aún muchos de ellos conservar el sabor y el colorido de los documentos originales. Este sistema, que importa la ausencia de toda crítica, no puede menos que dejarnos cuadros muy bellos y hermosos, pero falsos, del pasado. Michelet, Thierry. Chateaubriand. Merimée, representan esa tendencia. Para los sostenedores de este concepto, lo fundamental 
no es el fondo, sino la forma. Pero edesde hace cincuenta años, escriben dos eminentes historiadores. Seignobos y Langlois, se han separado y constituido las formas cientificas de exposición histórica, en armonía con la concepción general de que el fin de la historia no es agradar, ni dar preceplos prácticos para guiarse en la vida, ni conmover. sino saber simplementes. Es decir, investigar la verdad. Este concepto fué el que orientó la labor histórica de Barros Arana, y el que ha dado a su obra la solidez, autoridad y prestigio que admiran en ella sus compatriolas. Cuando se haga una revisión desapasionada y serena de la obra literaria de nuestro gran poligrafo, a la vista de las colecciones documentales y de las monografias publidadas en los últimos lustros, se llegará a la conclusión de que su labor, en lo fundamental, es inamovible, y que revisle caracteres de solidez capaces de desafiar confiadamente la prueba del tiempo. Hasta ahora los detractores de Barros Arana apenas si han logrado rectificar algunas de sus afirmaciones. en delalles insignificantes y ridiculos, sin importancia alguna. El dia que con espiritu desprevenido y honrada pluma se examine su formidable labor literaria, se admitirá la magnitud de su esfuerzo, se admitirá su probidad moral, se elogiará la sagacidad de sus conclusiones, y no se le discutirá el titulo de ser el historiador por antonomasía de nuestra nacionalidad, glorioso calificativo que no le regateará la posteridad. 